\title{
ExoDx Prostate Intelliscore
}

National Cancer Institute

\section{Source}

National Cancer Institute. ExoDx Prostate Intelliscore. NCI Thesaurus. Code C154472.

A proprietary non-invasive, urine-based, liquid biopsy for high-grade prostate cancer. It uses an exosomal RNA (exoRNA)-based assay. 